\title{
A Call to Action: Hospitalists' Role in Addressing Substance Use Disorder
}

\author{
Honora Englander, MD ${ }^{1,2 *}$, Kelsey C Priest, $\mathrm{PhD}, \mathrm{MPH}^{3,4}$, Hannah Snyder, $\mathrm{MD}^{5}$, \\ Marlene Martin, MD', Susan Calcaterra, MD, MPH, MSㄱ, Jessica Gregg, MD, PhD2,8
}

\begin{abstract}
${ }^{1}$ Division of Hospital Medicine, Department of Medicine, Oregon Health \& Science University, Portland, Oregon; ${ }^{2}$ Section of Addiction Medicine, Department of Medicine, Oregon Health \& Science University, Portland, Oregon; ${ }^{3}$ School of Medicine, MD/PhD Program, Oregon Health \& Science University, Portland, Oregon; ${ }^{4}$ School of Public Health, Oregon Health \& Science University-Portland State University, Portland, Oregon; ${ }^{5}$ Department of Family Medicine, University of California, San Francisco, California; ${ }^{6}$ Division of Hospital Medicine, Zuckerberg San Francisco General Hospital and the Department of Medicine, University of California, San Francisco School of Medicine, San Francisco, California; ${ }^{7}$ University of Colorado, Department of Medicine, Division of General Internal Medicine and Division of Hospital Medicine, Denver, Colorado; ${ }^{8}$ Division of General Internal Medicine, Department of Medicine, Oregon Health \& Science University, Portland, Oregon.
\end{abstract}

n 2017, the death toll from drug overdoses reached a record high, killing more Americans than the entire Vietnam War or the HIV/AIDS epidemic at its peak. ${ }^{1}$ Up to one-quarter of hospitalized patients have a substance use disorder (SUD) and SUD-related ${ }^{2,3}$ hospitalizations are surging. People with SUD have longer hospital stays, higher costs, and more readmissions. ${ }^{3,4}$ While the burden of SUD is staggering, it is far from hopeless. There are multiple evidence-based and highly effective interventions to treat SUD, including medications, behavioral interventions, and harm reduction strategies.

Hospitalization can be a reachable moment to initiate and coordinate addictions care. ${ }^{5}$ Hospital-based addictions care has the potential to engage sicker, highly vulnerable patients, many who are not engaged in primary care or outpatient addictions care. ${ }^{6}$ Studied effects of hospital-based addictions care include improved SUD treatment engagement, reduced alcohol and drug use, lower hospital readmissions, and improved provider experience. .9 $^{\text {-9 }}$

Most hospitals, however, do not treat SUD during hospitalization and do not connect people to treatment after discharge. Hospitals may lack staffing or financial resources to implement addiction care, may believe that SUDs are an outpatient concern, may want to avoid caring for people with SUD, or may simply not know where to begin. Whatever the reason, unaddressed SUD can lead to untreated withdrawal, disruptive patient behaviors, failure to complete recommended medical therapy, high rates of against medical advice discharge, poor patient experience, and widespread provider distress. ${ }^{8}$

Hospitalists-individually and collectively-are uniquely positioned to address this gap. By treating addiction effectively and compassionately, hospitalists can engage patients, improve care, improve patient and provider experience, and lower costs. This paper is a call to action that describes the current state of hospital-based addictions care, outlines key

*Corresponding Author: Honora Englander, MD; E-mail: englandh@ohsu.edu; Telephone: 503-494-1164; Twitter: @honoraenglander

Published online first October 23, 2019

Received: May 28, 2019; Revised: August 16, 2019;

Accepted: August 16, 2019

๑ 2020 Society of Hospital Medicine DOI 10.12788/jhm.3311 challenges to implementing SUD care in the hospital, debunks common misconceptions, and identifies actionable steps for hospitalists, hospital leaders, and hospitalist organizations.

\section{MODELS TO DELIVER HOSPITAL-BASED ADDICTIONS CARE}

Hospital-based addiction medicine consult services are emerging; they include a range of models, with variations in how patients are identified, team composition, service availability, and financing. ${ }^{10}$ Existing addiction medicine consult services commonly offer SUD assessments, psychological intervention, medical management of SUDs (eg, initiating methadone or buprenorphine), medical pain management, and linkage to SUD care after hospitalization. Some services also explicitly integrate harm reduction principles (eg, naloxone distribution, safe injection education, permitting patients to smoke). ${ }^{11}$ Additional consult service activities include hospital-wide SUD education, and creation and implementation of hospital guidance documents (eg, methadone policies). ${ }^{10}$ Some consult services utilize only physicians, while others include interprofessional providers, such as nurses, social workers, and peers with lived experience of addiction. Whereas addiction medicine physicians staff some consult services, hospitalists with less formal addiction credentials staff others.

Broadly, hospital-based addictions care cannot depend solely on consult services. Just as not all hospitals have cardiology consult services, not all hospitals will have addiction consult services. As such, hospitalists can play an even greater role by implementing order sets and guidelines, supporting partnerships with community SUD treatment, and independently initiating evidence-based medications.

\section{CHALLENGES TO ADOPTION AND IMPLEMENTATION OF HOSPITAL-BASED ADDICTIONS CARE}

Pervasive individual and structural stigmas ${ }^{12}$ are perhaps the most critical barriers to incorporating addiction medicine into routine hospital practice, and they are both cause and consequence of our system failures. Most medical schools and residencies lack SUD training, which means that the understanding of addiction as a moral deficiency or lack of willpower may remain unchallenged. Stigma surrounding SUDs contributes 
TABLE. Action Opportunities and Resources for Hospitalists, Hospital Leaders, and Hospitalist Organizations

\begin{tabular}{|c|c|c|c|}
\hline Action Opportunities & Hospitalists & Hospitalist Leaders & Hospitalist Organizations \\
\hline \multirow{2}{*}{ Clinical Management } & \multirow{2}{*}{$\begin{array}{l}\text { Prescribe naloxone at hospital discharge } \\
\text { Offer harm reduction resources (eg, clean syringes, fentanyl } \\
\text { test strips) } \\
\text { Practice trauma-informed care }\end{array}$} & $\begin{array}{l}\text { workflows } \\
\text { Develop pathways to post hospital community addictions }\end{array}$ & \multirow{2}{*}{$\begin{array}{l}\text { Publish and promote guidelines or position } \\
\text { statements supporting addiction care, including } \\
\text { medication for OUD in hospital settings }\end{array}$} \\
\hline & & $\begin{array}{l}\text { treatment (eg, office-based buprenorphine, methadone } \\
\text { clinics, syringe access services) }\end{array}$ & \\
\hline \multirow[t]{2}{*}{ Training and Certification } & \multirow{2}{*}{$\begin{array}{l}\text { Obtain a buprenorphine waiver } \\
\text { Participate in addiction medicine mentoring or training } \\
\text { programs }\end{array}$} & $\begin{array}{l}\text { Provide incentives and/or pay for hospitalists to complete } \\
\text { buprenorphine waiver training }\end{array}$ & $\begin{array}{l}\text { Support addiction medicine training at hospitalist } \\
\text { society meetings }\end{array}$ \\
\hline & & $\begin{array}{l}\text { Develop a staff education campaign on evidence-based } \\
\text { addiction treatment, trauma-informed care, harm reduction, } \\
\text { and avoiding stigma }\end{array}$ & $\begin{array}{l}\text { Lobby medical specialties to include addiction } \\
\text { medicine competencies in board certification and } \\
\text { maintenance of certification requirements }\end{array}$ \\
\hline \multirow[t]{2}{*}{ Stakeholder Engagement } & $\begin{array}{l}\text { Engage hospital- and community-based peer mentors, } \\
\text { social workers, counselors, case managers }\end{array}$ & $\begin{array}{l}\text { Identify and support SUD clinical champions } \\
\text { Develop addiction medicine consult services }\end{array}$ & \multirow{2}{*}{$\begin{array}{l}\text { Partner with addiction medicine societies and harm } \\
\text { reduction groups } \\
\text { Advocate with governmental leaders to reduce } \\
\text { barriers that restrict treatment access such as the } \\
\text { buprenorphine waiver }\end{array}$} \\
\hline & $\begin{array}{l}\text { Model and advocate for the use of nonstigmatizing } \\
\text { language when discussing SUD }\end{array}$ & $\begin{array}{l}\text { Organize a taskforce to coordinate diverse SUD efforts } \\
\text { across the hospital }\end{array}$ & \\
\hline \multirow[t]{7}{*}{ Resources } & \multirow{4}{*}{$\begin{array}{l}\text { National treatment guidelines }{ }^{14} \\
\text { Point-of-care clinical tools }{ }^{15,16} \\
\text { Free mentoring and online buprenorphine waiver trainings }{ }^{15} \\
\text { UCSF Telephone Warmline: clinician-to-clinician real-time } \\
\text { case support } 9 \text { AM to } 8 \text { PM EST }{ }^{17}\end{array}$} & \multirow{2}{*}{$\begin{array}{l}\text { California Bridge: acute care resources on buprenorphine } \\
\text { and methadone, including webinars, dosing guidelines, }\end{array}$} & \multirow{3}{*}{$\begin{array}{l}\text { Example position papers include: } \\
\text { American College of Emergency Physicians Position } \\
\text { Statement on Buprenorphine in the Emergency } \\
\text { Department }{ }^{23}\end{array}$} \\
\hline & & & \\
\hline & & patient materials ${ }^{16}$ & \\
\hline & & $\begin{array}{l}\text { IMPACT toolkittl } \\
\text { Recommendations for integrating peers into hospital care }{ }^{22}\end{array}$ & \multirow{4}{*}{$\begin{array}{l}\text { Society of Hospital Medicine Consensus Statement } \\
\text { on safe opioid prescribing }{ }^{24}\end{array}$} \\
\hline & Harm reduction in hospital reference ${ }^{18}$ & State and federal funding opportunities (eg, 2019 State & \\
\hline & Changing the Language of Addiction brief ${ }^{19}$ & & \\
\hline & $\begin{array}{l}\text { ECHO: remote telementoring that includes didactics and } \\
\text { case discussions }{ }^{20}\end{array}$ & & \\
\hline
\end{tabular}

Abbreviations: AUD, alcohol use disorder; ECHO, extensions for community healthcare outcomes; IMPACT: inpatient addiction medicine consult service; OUD, opioid use disorder; SUD, substance use disorder; UCSF, University of California, San Francisco.

to hospitalists' and hospital leaders' aversion to treating patients with SUD, and to fears that providing quality SUD care will attract patients suffering from these conditions.

Recent national efforts have focused on the problem of opioid overprescribing. Without an equal emphasis on treatment, this focus can lead to undertreatment of pain and/or opioid use disorder in hospitalized patients, particularly since most hospitalists have little to no training in diagnosing SUD, prescribing life-saving medications for opioid use disorder, or managing acute pain in patients with SUD. The focus on overprescribing also diverts attention away from trends involving stimulants, ${ }^{2}$ fentanyl contamination of the drug supply, ${ }^{13}$ and alcohol, all of which have important implications for the care of hospitalized adults.

Hospital policies are often not grounded in evidence (eg, recommending clonidine for first-line treatment of opioid withdrawal and not buprenorphine/methadone), and there are widespread misconceptions about perceived legal barriers to treating opioid use disorder in the hospital, which is both safe and legal. ${ }^{10}$ People with SUD may be unjustly viewed through a criminal justice lens. Policies focused on controlling visitors and conducting room searches disproportionately burden people with SUD, which may create further harms through reinforcing negative provider cognitive biases about SUDs. Finally, hospitals may lack inpatient social work and pharmacy supports, and they rarely have pathways to connect people to SUD care after discharge.

Funding remains a widespread challenge. While some hospital administrators support addiction medicine services because of the pressing medical need and public health crisis, most services depend on billing or demonstrated savings through reduced hospital days or readmissions.

\section{A CALL TO ACTION: HOW HOSPITALISTS CAN IMPROVE ADDICTION CARE}

Individual hospitalists, hospitalist leaders, and hospitalist organizations can engage by improving individual practice, driving systems change, and through advocacy and policy change (Table).

\section{Individual Hospitalists}

Providing basic addiction medicine care should be a core competency for all hospitalists, just as every hospitalist can initiate a goals-of-care conversation or prescribe insulin. For opioid use disorder, hospitalists should treat withdrawal and offer treatment initiation with opioid agonist therapy (ie, methadone, buprenorphine), which reduces mortality by over half. Commonly, hospitalized patients are subjected to harmful, nonevidence-based treatments, such as mandated rapid methadone tapers, ${ }^{25}$ which 
can lead to undertreated withdrawal, increased pain, and opioid cravings. This increases patients' risk for overdose after discharge and precludes them from receiving life-saving, evidence-based methadone maintenance, or buprenorphine treatment. Though widely misunderstood, prescribing methadone in the hospital is legal, and providers need no special waiver to prescribe buprenorphine during admission. Current laws require that hospitalists have a waiver to prescribe buprenorphine at discharge and prohibit hospitalists (or anyone outside of an opioid treatment program) from prescribing methadone for the treatment of opioid use disorder at discharge. Further, hospitalists should offer medication for alcohol use disorder (eg, naltrexone) and be good stewards of opioids during hospitalization, avoiding intravenous opioids where appropriate and curbing excessive prescribing at discharge. Given high rates of overdose and fentanyl contamination of stimulants, opioids, and benzodiazepines, hospitalists should prescribe naloxone at discharge to every patient with SUD, on chronic opioids, or who uses any nonmedical substances.

Resources exist for individual hospitalists seeking mentorship or additional training (Table). Though not necessary for in-hospital prescribing, hospitalists can obtain a waiver to prescribe buprenorphine at discharge (commonly called the $\mathrm{X}$-waiver). To qualify, physicians must complete eight hours of accredited training (online and/or in-person), after which they must request a waiver from the Drug Enforcement Administration. Advanced-practice practitioners must complete 24 hours of training. Many have argued that policymakers should end this waiver requirement. ${ }^{26}$ While we support efforts to " $X$ the $X^{\prime \prime}$ and urgently expand treatment access, additional training can enrich providers' knowledge and confidence to prescribe buprenorphine, and is a relatively simple way that all hospitalists could act. Finally, by treating addiction and modeling patient-centered addictions care, hospitalists can legitimize and destigmatize the disease of addiction, ${ }^{8}$ and have the potential to mentor and train students, residents, nurses, and other staff. 27

\section{Hospitalist Leaders}

As leaders, hospitalists can play a key role in promoting hospital-based addictions care and tailoring solutions to meet local needs. Leaders can promote a cultural shift away from stigma, and promote evidence-based, life-saving care. Hospitalist leaders could require all hospitalists to obtain buprenorphine waivers. Leaders could initiate quality improvement projects related to SUD service delivery, develop policies that support inpatient SUD treatment, develop order sets for medication initiation, engage community substance use treatment partners, build pathways to timely addiction care after discharge, and champion development of addiction medicine consult services.

Hospitalist leaders can reference open-source guidelines, order sets, assessment and treatment tools, patient materials, pharmacy and therapeutics committee materials, and other resources for implementing services for hospitalized patients with SUD (Table). ${ }^{21,22}$ Hospitalist leaders who understand finan- cial and quality drivers can also champion the business and quality case for hospital-based addictions care, and help pursue local and national funding opportunities.

\section{Hospitalist Organizations}

Hospitalist societies could provide training at regional and national conferences to upskill hospitalists to care for people with SUD; support addiction medicine interest groups; and partner with addiction medicine societies, harm reduction organizations, and organizations focused on trauma-informed care. They could endorse practice guidelines and position statements describing the crucial role of hospitalists in addressing the overdose crisis and offering medication for addiction ( $\mathrm{Ta}$ ble). Hospitalist organizations can engage national and state hospital associations, lobby medical specialties to include addiction medicine competencies in board certification requirements, and advocate with governmental leaders to reduce barriers that restrict treatment access such as the $\mathrm{X}$-waiver.

\section{MOVING FORWARD}

Regardless of whether a hospitalist is serving as an individual provider, a hospitalist leader, or as part of a hospitalist organization, hospitalists can take critical steps to advance the care of people with SUD. These steps shift the culture of hospitals from one where patients are afraid to discuss their substance use, to one that creates space for connection, treatment engagement, and healing. By starting medications, utilizing widely accessible resources, and collaborating with community treatment and harm reduction organizations, each one of us can play a part in addressing the epidemic.

\section{Acknowledgments}

The authors thank Alisa Patten for help preparing this manuscript. Dr. Englander would like to thank Dr. David Bangsberg and Dr. Christina Nicolaidis for their mentorship.

Disclosures: The authors have nothing to disclose.

Funding: An award from the National Institute on Drug Abuse (UG1 DA-015815) supported Dr Englander's time. A training grant from the National Institute on Drug Abuse (F30 DA044700) supported Dr Priest's time.

\section{References}

1. Weiss A, Elixhauser A, Barrett M, Steiner C, Bailey M, O'Malley L. Opioid-related inpatient stays and emergency department visits by state, 2009-2014. Statistical Brief \#219. Healthcare Cost and Utilization Project. 2016. https:// www.hcup-us.ahrq.gov/reports/statbriefs/sb219-Opioid-Hospital-Stays-EDVisits-by-State.jsp. Accessed May 21, 2019

2. Winkelman TA, Admon LK, Jennings L, Shippee ND, Richardson CR, Bart $\mathrm{G}$. Evaluation of amphetamine-related hospitalizations and associated clinical outcomes and costs in the United States. JAMA Netw Open. 2018;1(6):e183758. https://doi.org/10.1001/jamanetworkopen.2018.3758.

3. Ronan MV, Herzig SJ. Hospitalizations related to opioid abuse/dependence and associated serious infections increased sharply, 2002-12. Health Aff (Millwood). 2016:35(5):832-837. https://doi.org/10.1377/hlthaff.2015.1424.

4. Walley AY, Paasche-Orlow M, Lee EC, et al. Acute care hospital utilization among medical inpatients discharged with a substance use disorder diagnosis. J Addict Med. 2012;6(1):50-56. https://doi.org/10.1097/ADM.0b013e318231 de 51 .

5. Englander $\mathrm{H}$, Weimer $\mathrm{M}$, Solotaroff $\mathrm{R}$, et al. Planning and designing the Improving Addiction Care Team (IMPACT) for hospitalized adults with 
substance use disorder. J Hosp Med. 2017;12(5):339-342. https://doi. org/10.12788/jhm.2736

6. Velez $\mathrm{C}$, Nicolaidis $\mathrm{C}$, Korthuis $\mathrm{P}$, Englander H. "It's been an experience, a life learning experience": a qualitative study of hospitalized patients with substance use disorders. J Gen Intern Med. 2017;32(3):296-303. doi 10.1007/ s11606-016-3919-4.

7. Wakeman SE, Metlay JP, Chang Y, Herman GE, Rigotti NA. Inpatient addiction consultation for hospitalized patients increases post-discharge abstinence and reduces addiction severity. J Gen Intern Med. 2017;32(8):909-916. https://doi.org/10.1007/s11606-017-4077-z.

8. Englander H, Collins D, Perry SP, Rabinowitz M, Phoutrides E, Nicolaidis C. "We've learned it's a medical illness, not a moral choice": qualitative study of the effects of a multicomponent addiction intervention on hospital providers' attitudes and experiences. J Hosp Med. 2018;13(11):752-758. https://doi. org/10.12788/jhm.2993

9. McQueen J, Howe TE, Allan L, Mains D, Hardy V. Brief interventions for heavy alcohol users admitted to general hospital wards. Cochrane Database Syst Rev. 2011;10(8):CD005191 https://doi.org/10.1002/14651858.CD005191.pub3.

10. Priest KC, McCarty D. Role of the hospital in the 21st century opioid overdose epidemic: the addiction medicine consult service. J Addict Med. 2019:13(2):104-112. https://doi.org/10.1097/ADM.0000000000000496.

11. Weinstein ZM, Wakeman SE, Nolan S. Inpatient addiction consult service: expertise for hospitalized patients with complex addiction problems. Med Clin North Am. 2018;102(4):587-601. https://doi.org/10.1016/j.mcna.2018.03.001.

12. McNeil R, Small W, Wood E, Kerr T. Hospitals as a "risk environment": an ethno-epidemiological study of voluntary and involuntary discharge from hospital against medical advice among people who inject drugs. Soc Sci Med. 2014;105:59-66. https://doi.org/10.1016/j.socscimed.2014.01.010.

13. Ciccarone $D$. The triple wave epidemic: supply and demand drivers of the US opioid overdose crisis. Int J Drug Policy. 2019. pii: S0955-3959(19)30018-0. [Epub ahead of print]. https://doi.org/10.1016/j.drugpo.2019.01.010.

14. Substance Abuse and Mental Health Services Administration. TIP 63: Medications for Opioid Use Disorder-Executive Summary. February 2018. https:// store.samhsa.gov/product/TIP-63-Medications-for-Opioid-Use-Disorder-Executive-Summary/sma18-5063exsumm. Accessed August 8, 2019.

15. Providers Clinical Support System. Discover the rewards of treating patients with Opioid Use Disorders. https://pcssnow.org/. Accessed August 8, 2019.

16. California Bridge Program. Treatment Starts Here: Resources for the Treatment of Substance Use Disorders from the Acute Care Setting. https://www. bridgetotreatment.org/resources. Accessed August 7, 2019.

17. Clinical Consultation Center. Substance Use Resources. 2019. https://nccc. ucsf.edu/clinical-resources/substance-use-resources/. Accessed August 8, 2019.

18. Thakarar K, Weinstein ZM, Walley AY. Optimising health and safety of people who inject drugs during transition from acute to outpatient care: narrative review with clinical checklist. Postgrad Med J. 2016;92(1088):356-363. https:// doi.org/10.1136/postgradmedj-2015-133720.

19. Office of National Drug Control Policy. Changing the Language of Addiction. Washington, D.C. 2017. https://www.whitehouse.gov/sites/whitehouse.gov/ files/images/Memo\%20-\%20Changing\%20Federal\%20Terminology\%20Regrading\%20Substance\%20Use\%20and\%20Substance\%20Use\%20Disorders. pdf. Accessed August 8, 2019

20. The University of New Mexico. Project ECHO: A Revolution in Medical Education and Care Delivery. 2019. https://echo.unm.edu/. Accessed August 8, 2019.

21. Englander $H$, Mahoney S, Brandt $K$, et al. Tools to support hospital-based addiction care: core components, values, and activities of the Improving Addiction Care Team. J Addict Med. 2019;13(2):85-89. https://doi.org/10.1097/ ADM.0000000000000487.

22. Englander H, Gregg J, Gollickson J, et al. Recommendations for intergrating peer mentors in hospital-based addiction care. Subst Abus. In press. https:// doi.org/10.1080/08897077.2019.1635968

23. American College of Medical Toxicology. ACMT Position Statement: Buprenorphine Administration in the Emergency Department. https://www. acep.org/globalassets/sites/acep/media/equal-documents/policy_acmt_ bupeadministration.pdf. Accessed May 21, 2019.

24. Herzig SJ, Mosher HJ, Calcaterra SL, Jena AB, Nuckols TK. Improving the safety of opioid use for acute noncancer pain in hospitalized adults: a consensus statement from the society of hospital medicine. J Hosp Med. 2018;13(4):263-271. https://doi.org/10.12788/jhm.2980.

25. Winetsky D, Weinrieb RM, Perrone J. Expanding treatment opportunities for hospitalized patients with opioid use disorders. J Hosp Med. 2018;13(1):6264. https://doi.org/10.12788/jhm.2861

26. Frank JW, Wakeman SE, Gordon AJ. No end to the crisis without an end to the waiver. Subst Abus. 2018;39(3):263-265. https://doi.org/10.1080/0889707 7.2018.1543382.

27. Gorfinkel L, Klimas J, Reel B, et al. In-hospital training in addiction medicine: a mixed-methods study of health care provider benefits and differences. Subst Abus. 2019. In press. https://doi.org/10.1080/08897077.2018.1561596. 